\title{
Age at menopause as a risk factor for cardiovascular mortality
}

\author{
Yvonne T van der Schouw, Yolanda van der Graaf, Ewout W Steyerberg, Marinus J C Eijkemans, Jan Dirk Banga
}

\section{Summary}

Background Although an association of occurrence of menopause and subsequent oestrogen deficiency with increased cardiovascular disease has been postulated, studies on this association have not shown convincing results. We investigated whether age at menopause is associated with cardiovascular mortality risk.

Methods We studied a cohort of 12115 postmenopausal women living in Utrecht, Netherlands, aged $50-65$ years at enrolment in a breast cancer screening project. During follow-up of up to 20 years the women attended screening rounds at which we asked questions on menopausal status, age at menopause, medication use, cardiovascular risk factors, and ovarian function. Deaths were ascertained from the patient's family physicians. Life-table analysis and cox regression analysis were used to investigate the association between age at menopause and cardiovascular mortality. All analyses were adjusted for biological age.

Findings 824 women died of cardiovascular causes. 1459 women had left the study area. The risk of cardiovascular mortality was higher for women with early menopauses than for those with late menopauses. The age-adjusted hazard ratio of age at menopause was $0.982(95 \% \mathrm{cl}$ $0.968-0.996, p=0.01$ ) -ie, for each year's delay in the menopause the cardiovascular mortality risk decreased by $2 \%$. The extra risk of early menopause seemed to decrease with biological age ( $p$ for interaction 0.07 ); at biological age 60 the reduction of the annual hazard was $3 \%$, but at age 80 there was no reduction. Adjustment for known cardiovascular risk factors and indicators of ovarian function did not significantly alter the risk estimate.

Interpretation These results support the hypothesis that longer exposure to endogenous oestrogens protects against cardiovascular diseases. The effect of an early menopause may be more important at younger biological ages.

Lancet 1996; 347: 714-18

\section{Introduction}

Premenopausal women seem to be protected against cardiovascular morbidity and mortality in comparison with men of similar age or postmenopausal women.1-3 Loss of ovarian function and subsequent deficiency of endogenous oestrogens is suggested to promote cardiovascular disease and death after menopause. ${ }^{4,5}$

If endogenous oestrogens protect against cardiovascular disease, an early menopause might incur a higher risk, because of lower exposure to oestrogens. Evidence for this hypothesis has been inconclusive. ${ }^{6}$ Several investigations had small samples ${ }^{5,7-9}$ and angina pectoris was used as the endpoint in some. ${ }^{5,10,11}$ The two prospective studies that have been done, the Framingham Heart Study ${ }^{2}$ and the Nurses' Health Study, ${ }^{3}$ were better designed to address the question of whether the menopause itself is a risk factor for cardiovascular disease than to show whether an early menopause poses a particular risk. The main problem of studies done so far is the short postmenopausal follow-up period, which has probably been too short for cardiovascular diseases to occur in sufficient frequency for statistical analysis.

To explore the relation between the age at menopause and subsequent cardiovascular mortality, we studied a cohort of postmenopausal women aged 50-65 years at enrolment in an experimental breast cancer screening project in 1974-77; the women were followed up for a median of 16 years (range $1-20$ years).

\section{Patients and methods}

\section{Patients}

Between December, 1974, and September, 1977, $14697(72 \%)$ of the 20555 women born between 1911 and 1925, living in the city of Utrecht, Netherlands, were enrolled in the DOM Project. ${ }^{12}$ The breast cancer screening was repeated several times (maximum four; women dropped out between rounds). 2203 of the women were within a year of their last menstrual period and were deemed premenopausal. The remaining 12494 reported that menses had ceased at least 12 months previously, and they were classified as postmenopausal. We excluded data for 1004 of the 2203 premenopausal women for whom the age at menopause could not be calculated from follow-up data, because they did not attend further screening sessions. Data for 1199 women who became menopausal during follow-up were included in the analysis, starting from the year they became postmenopausal. Data for 1578 women were excluded because of use of oestrogen replacement therapy, and the self-reported age at menopause was probably not reliable. Thus, 12115 women were included in the present analysis.

Municipal registries informed the Epidemiology Department each month about moves and deaths of cohort members. At the end of the follow-up period (Dec 31, 1994) 1459 women (12\% of the population) had moved outside the DOM area. The median follow-up for these women was 10 years, with a maximum of 20 years (whole cohort median 16, maximum 20 years). Cause of death was ascertained from the women's general practitioners. During the 20 years of follow-up (202 717 womenyears), 2022 women died, 824 of cardiovascular diseases, 726 of 


\begin{tabular}{|c|c|c|c|c|c|}
\hline \multirow[t]{2}{*}{ Characteristic } & \multicolumn{5}{|c|}{ Age at menopause (years) } \\
\hline & $\begin{array}{l}\leqslant 39 \\
(n=459)\end{array}$ & $\begin{array}{l}40-44 \\
(n=1344)\end{array}$ & $\begin{array}{l}45-49 \\
(n=3713)\end{array}$ & $\begin{array}{l}50-54 \\
(n=5741)\end{array}$ & $\begin{array}{l}\geqslant 55 \\
(n=858)\end{array}$ \\
\hline Age at entry (years) ${ }^{\star}$ & $56 \cdot 8(4.4)$ & $57 \cdot 3(4 \cdot 5)$ & $57 \cdot 1(4 \cdot 5)$ & $57.6(4-0)$ & $59.1(3 \cdot 0)$ \\
\hline Year of birth* & $1918.6(4 \cdot 3)$ & $1918.0(4.3)$ & $1918 \cdot 1(4 \cdot 3)$ & $1917 \cdot 8(4 \cdot 0)$ & $1917 \cdot 3(4 \cdot 1)$ \\
\hline \multicolumn{6}{|l|}{ Type of menopause } \\
\hline Natural & $193(42 \%)$ & $749(56 \%)$ & $2895(78 \%)$ & $5247(91 \%)$ & $777(91 \%)$ \\
\hline Hysterectomy & $82(18 \%)$ & $216(16 \%)$ & $324(9 \%)$ & $154(3 \%)$ & $15(2 \%)$ \\
\hline Oophorectomy & $116(25 \%)$ & $222(17 \%)$ & $303(8 \%)$ & $209(4 \%)$ & $37(4 \%)$ \\
\hline Radiation/surgery type unknown & $68(15 \%)$ & $157(12 \%)$ & $191(5 \%)$ & $131(2 \%)$ & $29(3 \%)$ \\
\hline Oral contraceptive use (ever use) & 1 & $39(3 \%)$ & $200(5 \%)$ & $424(7 \%)$ & $66(8 \%)$ \\
\hline \multicolumn{6}{|l|}{ Parity/age at first delivery } \\
\hline Nulliparous & $96(21 \%)$ & $258(19 \%)$ & $703(19 \%)$ & $1039(18 \%)$ & $144(17 \%)$ \\
\hline Age at first del/very $\leqslant 24$ years & $175(38 \%)$ & $671(50 \%)$ & $1840(49 \%)$ & $3071(54 \%)$ & $490(57 \%)$ \\
\hline Age at first delivery $>24$ years & $188(41 \%)$ & $415(31 \%)$ & $1170(32 \%)$ & $1631(28 \%)$ & $224(26 \%)$ \\
\hline \multicolumn{6}{|l|}{ Body fat } \\
\hline Body-mass Index $\geqslant 30 \mathrm{~kg} / \mathrm{m}^{2}$ & $97(21 \%)$ & $204(15 \%)$ & $555(15 \%)$ & $903(16 \%)$ & $149(17 \%)$ \\
\hline Upper-body fat distribution & $45(10 \%)$ & $150(11 \%)$ & $424(11 \%)$ & $714(12 \%)$ & $124(14 \%)$ \\
\hline \multicolumn{6}{|l|}{ Smoking status } \\
\hline Current smoker & $118(26 \%)$ & $299(22 \%)$ & $850(23 \%)$ & $1112(19 \%)$ & $122(14 \%)$ \\
\hline Non-smoker & $235(51 \%)$ & $750(56 \%)$ & $2110(57 \%)$ & $3520(61 \%)$ & $614(72 \%)$ \\
\hline Unknown & $106(23 \%)$ & $295(22 \%)$ & $753(20 \%)$ & $1109(19 \%)$ & $122(14 \%)$ \\
\hline Total cholesterol $(\mathrm{mmol} / \mathrm{L})^{*} \dagger$ & $6.5(1.2)$ & $6.5(1.1)$ & $6 \cdot 6(1.1)$ & $6.5(1.1)$ & $6.2(1.0)$ \\
\hline & $(n=88)$ & $(n=242)$ & $(n=652)$ & $(n=1041)$ & $(n=156)$ \\
\hline \multicolumn{6}{|l|}{ Hypertension } \\
\hline Present & $367(80 \%)$ & $1008(75 \%)$ & $2775(75 \%)$ & $4327(75 \%)$ & $679(79 \%)$ \\
\hline Unknown & $18(4 \%)$ & $85(6 \%)$ & $206(6 \%)$ & $368(6 \%)$ & $55(6 \%)$ \\
\hline Dlabetes & $11(2 \%)$ & $51(4 \%)$ & $113(3 \%)$ & $159(3 \%)$ & $31(4 \%)$ \\
\hline \multicolumn{6}{|l|}{ Previous cardiovascular disease } \\
\hline Present & $42(9 \%)$ & $104(8 \%)$ & $235(6 \%)$ & $373(7 \%)$ & $63(7 \%)$ \\
\hline Unknown & $101(22 \%)$ & $282(21 \%)$ & $739(20 \%)$ & $1074(19 \%)$ & $118(14 \%)$ \\
\hline
\end{tabular}

*Mean (SD). Other data are number (\%). † Measured in a subsample.

\section{Table 1: Distribution of baseline cardiovascular risk factors}

cancer, 94 from injury or external causes, including accidents and suicides, and 378 from other causes.

Questionnaires on menopausal status, age at menopause, medication use, cardiovascular risk factors, and indicators of ovarian function were completed at each screening visit. Menopause was defined as cessation of menstrual bleeding for at least 12 months. Hypertension was defined as systolic blood pressure of $160 \mathrm{~mm} \mathrm{Hg}$ or more, diastolic blood pressure of $90 \mathrm{~mm} \mathrm{Hg}$ or more, use of antihypertensive medication, or a combination of these features. Women were classified as diabetic if they reported use of oral hypoglycaemic drugs or insulin or were on a diabetes diet. In the original questionnaire, previous or present cardiovascular disease was recorded as ischaemic cerebral attacks or myocardial infarction up to 5 years before the second screening visit or use of medication for cardiovascular diseases. This medication consisted of aminoglycosides, antiarrhythmic drugs, nitrates, other antianginal drugs, or anticoagulants. Oral contraceptive use was coded as never use or ever use in statistical analyses, since the number of the women taking oral contraceptives was too small for detailed analysis. Parity and age at first delivery were classified in three categories-no children, children before or at age 24, and children after age 24 . Height, weight, and subscapular and triceps skinfold thicknesses were measured at the first screening visit. Body-mass index was calculated and dichotomised at $30 \mathrm{~kg} / \mathrm{m}^{2}$ or more. Skinfold thicknesses were measured with callipers that could not measure skinfolds thicker than $40 \mathrm{~mm}$, so such skinfolds were coded as $40 \mathrm{~mm}$ on the original registration forms. The study population was divided into subgroups by quintiles of subscapular as well as triceps skinfolds, resulting in subgroups of women with equally distributed fat, peripheral obesity, and upper-body obesity, respectively. ${ }^{13}$

Total cholesterol was measured in a sample of the population (2179). Blood pressure measurements started only after the first 961 women had been screened, and are thus missing for those women. This subgroup was large enough for these data to be included as a separate category of the hypertension variable in statistical analyses. Data on smoking and previous cardiovascular diseases were collected at the second screening visit, 1.5 years after the first visit, and are therefore not known for women who did not attend the second screening (2458). These data are also considered as separate categories in the statistical analysis.

The endpoint of the analysis was total cardiovascular mortality, codes 390-459 of the International Classification of Diseases, Ninth Revision (ICD-9). Death from other causes, loss to followup due to moving outside the DOM area, and withdrawal from the study were censoring events.

The association of age at menopause and cardiovascular mortality was first assessed by annual hazard estimates for biological ages between 50 and $80 .^{14}$ Biological age was a continuous variable, and age at menopause was classified in five categories $(<40,40-44,45-49,50-54,>54)$. Annual hazards were smoothed with a bandwidth of 5 years, and $95 \%$ CI were calculated.

Cox regression analysis was used to quantify further the effect of age at menopause on cardiovascular mortality. Since biological age is a major risk factor for cardiovascular mortality, all analyses were adjusted for age. This adjustment was done with biological age as the time axis. Since age at entry varied between 50 and 65 , we had to account for left truncation of the data caused by the staggered entry. Age at menopause was analysed as a continuous variable, with the assumption of a linear relation between age at menopause and cardiovascular mortality. This approach implies that a menopause delay of 1 year has identical effects over the entire range of menopause ages. We used a restricted cubic spline

\begin{tabular}{|c|c|c|c|c|c|}
\hline \multirow{2}{*}{$\begin{array}{l}\text { Age at } \\
\text { menopause } \\
\text { (years) }\end{array}$} & \multirow[t]{2}{*}{$\begin{array}{l}\text { Women-years } \\
\text { of follow-up }\end{array}$} & \multirow{2}{*}{$\begin{array}{l}\text { Number } \\
\text { of } \\
\text { events }\end{array}$} & \multicolumn{3}{|c|}{$\begin{array}{l}\text { Annual hazard of cardiovascular mortality } \\
(95 \% \mathrm{Cl}) \text { at biological age: }\end{array}$} \\
\hline & & & 65 years & 70 years & 75 years \\
\hline$\leqslant 39$ & 7650 & 43 & $4.9(2.5-7.3)$ & $6.6(3.5-9.7)$ & $13 \cdot 1(6 \cdot 9-19 \cdot 2)$ \\
\hline $40-44$ & 22559 & 99 & $3.4(2.2-4.5)$ & $5.7(4.1-7.4)$ & $8.2(5.6-10.8)$ \\
\hline & 62163 & 238 & $3.2(2.6-3.9)$ & $4 \cdot 4(3.5-5 \cdot 2)$ & $7 \cdot 1(5 \cdot 6-8 \cdot 6)$ \\
\hline & 96482 & 391 & $2 \cdot 6(2 \cdot 1-3 \cdot 1)$ & $4.7(4.0-5.4)$ & $8 \cdot 8(7 \cdot 5-10 \cdot 1)$ \\
\hline$\geqslant 55$ & 13863 & 53 & $2 \cdot 7(1-4-4 \cdot 1)$ & $4.3(2.6-6.0)$ & $7.0(4 \cdot 2-9.9)$ \\
\hline
\end{tabular}

Table 2: Annual hazards of cardiovascular mortality for women at biological ages 65,70 , and 75 in relation to age at menopause 


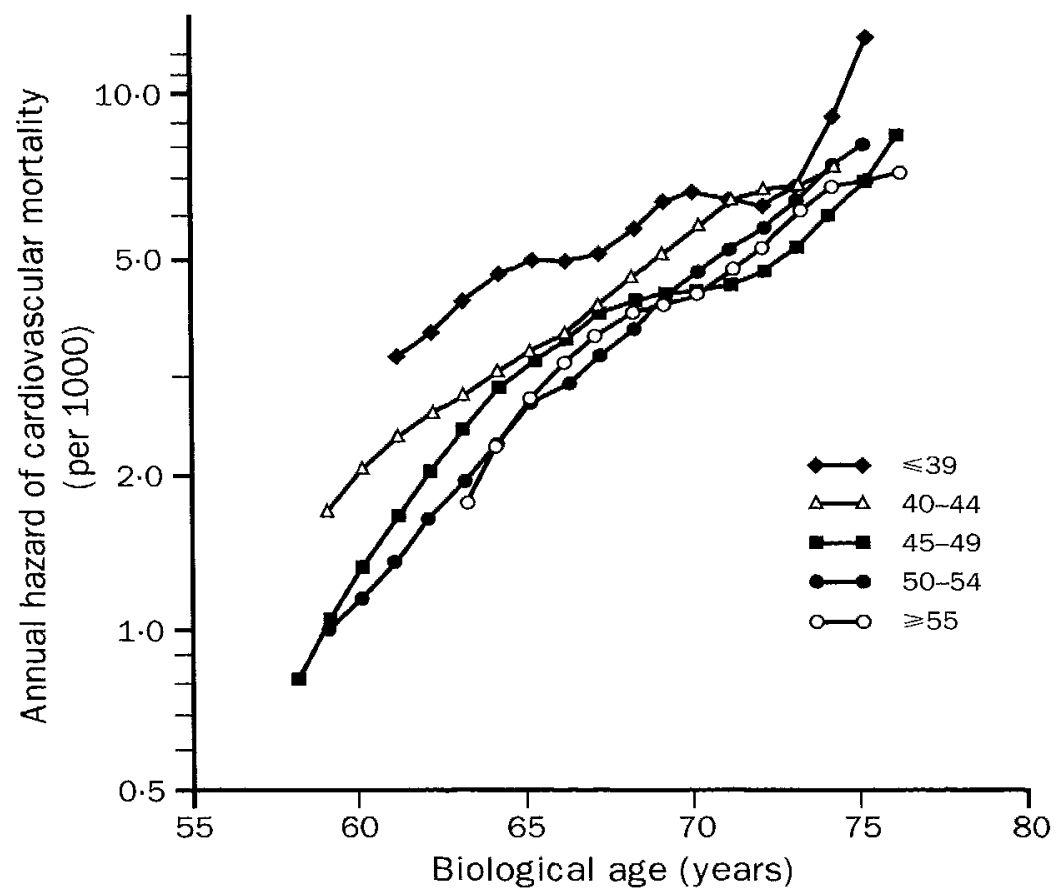

Figure: Annual hazard of cardiovascular mortality (logarithmic scale) in relation to age at menopause

For proportional hazards, the lines should be parallel.

function of age at menopause with three knots to test the linearity assumption. The use of such a function has been proposed as a statistically efficient procedure to detect non-linearity. ${ }^{15}$ The Cox model further assumes that the hazards are proportional over time.

Proportionality of the effect of age at menopause was examined graphically in a plot of the logarithm of the annual hazards and was statistically tested by the addition to the Cox model of the interaction term of age at menopause and biological age. Because age at entry varied between 50 and 65, a cohort effect may have confounded the association at issue. This was approximated by year of birth. To study whether year of birth or other known cardiovascular risk factors caused confounding, we entered them first individually and then simultaneously into the Cox model with age at menopause to see whether the crude hazard ratio of age at menopause changed substantially. The effects of age at menopause were investigated in predetermined subgroups: women with different types of menopause (natural, hysterectomy, oophorectomy, radiation/surgery type unknown), and smokers and non-smokers. To test the significance of the subgroup effects, interaction terms of age at menopause with type of menopause and smoking were added to the Cox model, respectively.

\section{Results}

Baseline characteristics were distributed similarly among the strata of age at menopause (table 1). Oral contraceptive use was rare among these women, who were aged $37-52$ when oral contraceptives were introduced in the Netherlands.

The risk of cardiovascular mortality was higher at all three biological ages analysed for women who had early menopauses (table 2). For example, the annual hazard of cardiovascular death at age 70 was $5 \cdot 7 \%$ when the menopause occurred at age $40-44$ and $4 \cdot 3 \%$ when menopause occurred at age 55 or later. We quantified the hazard ratio of age at menopause, adjusted for age, as $0.982(95 \%$ CI $0.968-0.996)$. Thus, each year that the menopause is delayed decreases the annual hazard of cardiovascular death by $2 \%$. For example, a woman with menopause at age 45 has a risk of cardiovascular death 0.98 times that of a woman who has her menopause at age 44 .

The effect of age at menopause on cardiovascular mortality was reasonably linear $(p=0.35)$. This finding

\begin{tabular}{|c|c|}
\hline \multirow[b]{2}{*}{ Crude, adjusted only for blologlcal age } & \\
\hline & $0.982(0.968-0.996)$ \\
\hline Adjusted for all varlables simultaneously & $0.983(0.975-0.998)$ \\
\hline \multicolumn{2}{|l|}{ Adjusted for single varlables } \\
\hline Year of bırth & $0.982(0.968-0.996)$ \\
\hline Natural menopause & $0.981(0.966-0.996)$ \\
\hline Oral contraceptive use & $0.983(0.969-0.998)$ \\
\hline Parity/age at first delivery & $0.983(0.969-0.998)$ \\
\hline Body-mass index $\geqslant 30 \mathrm{~kg} / \mathrm{m}^{2}$ & $0.982(0.968-0.997)$ \\
\hline Upper-body fat distribution & $0.982(0.969-0.996)$ \\
\hline Smokıng & $0.985(0.971-0.999)$ \\
\hline Hypertension & $0.982(0.968-0.996)$ \\
\hline Diabetes & $0.982(0.968-0.996)$ \\
\hline Previous cardiovascular disease & $0.984(0.969-0.998)$ \\
\hline
\end{tabular}

Table 3: Hazard ratio of age at menopause and cardiovascular mortality adjusted for potential confounders

\begin{tabular}{|c|c|c|}
\hline Subgroup & n & Hazard ratio $(95 \% \mathrm{Cl})$ \\
\hline \multicolumn{3}{|l|}{ Type of menopause } \\
\hline Natural & 9861 & $0.985(0.967-1.003)$ \\
\hline Hysterectomy & 791 & $1.010(0.941-1.084)$ \\
\hline Oophorectomy & 887 & $0.940(0.901-0.981)$ \\
\hline Radiatıon/type of surgery unknown & 576 & $0.979(0.930-1.031)$ \\
\hline \multicolumn{3}{|l|}{ Smoking status } \\
\hline Non-smoker & 7220 & $0.976(0.957-0.997)$ \\
\hline Current smoker & 2510 & $1.007(0.978-1.037)$ \\
\hline Unknown & 2385 & $0.985(0.957-1.014)$ \\
\hline
\end{tabular}

Table 4: Relation of age at menopause with cardiovascular mortality for subgroups of type of menopause and smoking

means that the difference in effect of age at menopause on cardiovascular mortality between each pair of two consecutive menopausal years is equal-ie, a menopause delay of 1 year at age 40 has the same effect as a 1-year delay at age 50 .

The extra risk of cardiovascular mortality due to early menopause seemed to decrease with increasing biological age, although the difference had borderline significance $(p=0.07)$. The cardiovascular mortality risks clearly differed among the age at menopause subgroups at biological age 60 , but they were more similar at age 80 (figure). The estimated effect of each year of delay in menopause is a reduction in annual hazard of $3 \%$ for a woman of biological age $65,2 \%$ for a 70 -year-old, $1 \%$ for a 75-year-old, and no reduction for an 80-year-old.

Individually, none of the baseline variables influenced the estimation of the average hazard ratio. The hazard ratio adjusted for all variables simultaneously was 0.983 (95\% CI $0.975-0.998)$ so confounding by known cardiovascular risk factors is negligible (table 3). For women who had undergone hysterectomy, age at menopause was not associated with cardiovascular mortality (table 4). By contrast, for those who had had oophorectomy the effect might be stronger, although the differences in these hazard ratios were not significant ( $p$ for interaction 0.21 ). The hazard ratio for age at menopause was 1.007 in smokers and 0.976 in nonsmokers, although again this difference was not significant ( $\mathrm{p}$ for interaction $0 \cdot 22$; table 4 ).

\section{Discussion}

Our results clearly show an increased risk of cardiovascular mortality for women who have early menopause. Biases may have led to incorrect effect estimates. Selection bias could have led to an underestimation. Women had to survive until at least age 50 to be invited for screening. Furthermore, they had to be healthy enough to attend screening. Women who later died of cardiovascular disease were more likely to 
withdraw between screening rounds. Thus, women attending the first screening were probably at lower cardiovascular risk. Reanalysis of the data including only women who attended at least the second screening round, however, gave similar results. Underestimation of the effect of early menopause due to selection bias will therefore be slight.

Although the study design was prospective, $85 \%$ of the women were already postmenopausal at enrolment, which could lead to misclassification bias. Age at menopause as reported at the first screening round was compared with that reported in the fifth round, 7.5 years later, in a sample of 4892 women. For $80 \%$ of the sample the two reports differed by at most 1 year; thus, misclassification was limited. The findings are similar to those of the Nurses' Health Study. ${ }^{16}$

Biased reporting and measurement of risk factors by women with an early menopause is an unlikely explanation for our results. Associations of type of menopause, parity and age at first delivery, oral contraceptive use, smoking behaviour, and body-mass index with age at menopause have been reported previously. ${ }^{17-20}$ Hypertension, total cholesterol, body-fat distribution, presence of diabetes, and previous cardiovascular events are known risk factors for cardiovascular mortality. Adjustment for potential confounders was achieved by adding these factors individually or simultaneously into the Cox model. For parity we also checked whether the number of children was a potential confounder, and found that it was not. Information on lipoprotein fractions and subfractions was not available. However, since lipid concentrations are probably involved in the biological mechanism of the effect of oestrogens on cardiovascular diseases, it would be inappropriate to adjust for lipid concentrations. Reanalysis of the data for women with complete data only gave similar results for the estimated hazard ratios. The possibility of ineffective adjustment caused by inclusion of missing data as separate categories of variables can therefore be excluded.

The effect of age at menopause on cardiovascular mortality was absent for women who had undergone hysterectomy and stronger for those who had had oophorectomy. This difference, although not statistically significant, is consistent with the postulated biological mechanism that hysterectomy does not lead to immediate cessation of oestrogen production, whereas oophorectomy does.

Smoking advances the age of natural menopause by about 1.5 years. ${ }^{21}$ The effect of age at menopause may be expected to differ between smokers and non-smokers, because smokers become menopausal even earlier. Although the effect of age at menopause in the various smoking subgroups did not differ significantly, the hazard ratio of age at menopause was almost unity for smoking women. The effect of smoking on cardiovascular mortality seems to be so strong as to over-ride the effect of an early menopause.

The evidence that reduced exposure to endogenous oestrogens leads to increased cardiovascular morbidity has mainly come from studies of postmenopausal exogenous oestrogen replacement, ${ }^{6}$ for which a relative risk of 0.56 (95\% CI $0.50-0 \cdot 61)$ has been estimated. ${ }^{22}$ Morbidity and mortality statistics suggest that the decrease in the gap between cardiovascular morbidity and mortality in men and women cannot be attributed to the menopause..$^{9,23-25}$
Studies on the effect of endogenous oestrogens on the occurrence of cardiovascular disease have been inconclusive. ${ }^{2,5,26,27}$ The only prospective studies reported inconsistent results. ${ }^{2,3}$ The Framingham Heart Study reported higher risk of cardiovascular disease in postmenopausal women that was even more pronounced in women aged 40-44 years, ${ }^{2}$ whereas the Nurses' Health Study found no significant association with time since natural menopause. ${ }^{3}$ In both cohorts, the women were young for cardiovascular disease to occur, less than 55 and 61 years old, respectively, and the time from menopause to cardiovascular disease may have been too short to allow convincing results to be shown. By contrast, in our study the oldest women were 85 years old and the postmenopausal follow-up extended to a maximum of 20 years.

The only investigation in which plasma concentrations of oestrogens were measured did not show any association with cardiovascular mortality. ${ }^{27}$ However, plasma concentrations were measured in postmenopausal women, and such measurements do not necessarily reflect premenopausal hormone concentrations.

In conclusion, our study provides evidence that early menopause is an independent risk factor for cardiovascular mortality and supports the hypothesis that reduced endogenous oestrogen exposure increases cardiovascular mortality risk. The effect of an early menopause may be more important at younger biological ages.

The study was supported by grant 92.361 from the Netherlands Heart Foundation.

\section{References}

1 Kannel WB, Hjortland MC, McNamara PM, Gordon T. Menopause and the risk of cardiovascular disease: the Framingham study. Ann Intern Med 1976; 85: 447-52.

2 Gordon T, Kannel WB, Hjortland MC, McNamara PM. Menopause and coronary heart disease: the Framingham study. Ann Intern Med 1978; 89: 151-61.

3 Colditz GA, Willett WC, Stampfer MJ, Rosner B, Speizer FE, Hennekens $\mathrm{CH}$. Menopause and the risk of coronary heart disease in women. $N$ Engl 7 Med 1987; 316: 1105-10.

4 Parrish HM, Carr CA, Hall DG, King TM. Time interval from castration in premenopausal women to development of excessive coronary atherosclerisis. Am f Obstet Gynecol 1967; 99: 155-62.

5 Robinson RW, Higano N, Cohen WD. Increased incidence of coronary heart disease in women castrated prior to the menopause. Arch Intern Med 1959; 104: 908-13.

6 Barrett-Connor EL, Bush TL. Estrogen and coronary heart disease in women. $\mathcal{F} A M A$ 1991; 265: 1861-67.

7 Wuest JH, Dry TJ, Edwards JE. The degree of coronary atherosclerosis in bilaterally oophorectomised women. Circulation 1953; 8: 801-08.

8 Rivin AU, Dimitroff SP. The incidence and severity of cornary atherosclerosis in estrogen-treated males, and in females with a hypoestrogenic or a hyperestrogenic state. Circulation 1954; 9: 533-39.

9 Winkelstein W, Stichever MA, Lilienfield AM. Occurrence of pregnancy, abortion and artificial menopause among women with coronary artery disease. $\mathcal{F}$ Chron Dis 1958; 7: 273-86.

10 Bengtsson $C$, Rybo $G$, Westerberg $H$. Number of pregnancies, use of oral contraceptives and menopausal age in women with ischaemic heart disease, compared to a population sample of women. Acta Med Scand 1973; 89 (suppl): 75-81.

11 Beard CM, Fuster V, Annegers JF. Reproductive history in women with coronary heart disease: a case control study. Am f Epidemiol 1984; 120: 108-14.

12 Waard de F, Collette HJA, Rombach JJ, Baanders-van Halewijn EA Honing $C$. The DOM-project for early diagnosis of breast cancer. 7 Chron Dis 1984; 47: 41-44.

13 Tonkelaar den I, Seidell JC, Collette HJA, Waard de F. A prospective study on obesity and subcutaneous fat patterning in relation to breast cancer in post-menopausal women participating in the DOM project. Brf Cancer 1994; 69: 352-57.

14 Breslow NE, Day NE. Statistical methods in cancer research, volume II. The design and analysis of cohort studies. Oxford: Oxford University Press, 1987: 195. 
15 Harrell FE Jr, Lee KL, Pollock BG. Regression models in clinical studies: determining relationships between predictors and response. $\mathcal{F}$ Natl Cancer Inst 1985; 80: 1198-202.

16 Colditz GA, Stampfer MJ, Willett WC, et al. Reproducibility and validity of self-reported menopausal status in a prospective cohort study. Am F Eprderniol 1987; 126: 319-25.

17 Stanford JL, Hartge P, Brinton LA, Hoover RN, Brookmeyer R. Factors influencing the age at natural menopause. $\mathcal{F}$ Chron Dis 1987; 40: $995-1002$

18 Midgette AS, Baron JA. Cigarette smoking and the risk of natural menopause. Epidemiology 1990; 1: 474-80.

19 Luoto R, Kaprio J, Uutela A. Age at natural menopause and sociodemographic status in Finland. Am J Epidemiol 1994; 139: 64-76.

20 Stampfer MJ, Colditz GA, Willett WC. Menopause and heart disease: a review. Ann N Y Acad Sci 1990; 592: 193-203.

21 Brambilla DJ, McKinlay SM. A prospective study of factors affecting age at menopause. 7 Clin Epidemiol 1989; 42: 1031-39.

22 Stampfer MJ, Colditz GA. Estrogen replacement therapy and coronary heart disease: a quantitative assessment of the epidemiologic evidence. Prcv Med 1991; 20: 47-63.

23 Corrao JM, Becker RC, Ockene IS, Hamilton GA. Coronary heart disease risk factors in women. Cardiology 1990; 77 (suppl): 8-24.

24 Tracey RE. Sex differences in coronary artery disease: two opposing views. $f$ Chron Dis 1966; 19: 1245-51.

25 Heller RF, Jacobs HS. Coronary heart disease in relation to age, sex, and the menopause. BMF 1978; i: 472-74.

26 Rosenberg L, Hennekens CH, Rosner B, Belanger C, Rothman KJ, Speizer FE. Early menopause and the risk of myocardial infarction. Am $\mathcal{F}$ Obstet Gynecol 1981; 139: 47-51.

27 Barrett-Connor EL, Goodman-Gruen D. Prospective study of endogenous sex hormones and fatal cardiovascular disease in postmenopausal women. BMF 1995; 311: 1193-96.

\title{
Invasive pneumococcal disease in a cohort of predominantly HIV-1 infected female sex-workers in Nairobi, Kenya
}

\author{
Charles F Gilks, Sylvia A Ojoo, Josephine C Ojoo, Richard J Brindle, John Paul, Barry I F Batchelor, Joseph N Kimari, \\ Robert Newnham, Joab Bwayo, Francis A Plummer, David A Warrell
}

\section{Summary}

Background HIV infection is a major risk factor for pneumococcal disease in industrialised countries. Although both are common infections in sub-Saharan Africa, few studies have investigated the importance of this interaction. We have followed up a cohort of female sexworkers in Nairobi and report here on the extent of invasive pneumococcal disease.

Methods A well-established cohort of low-class female sexworkers, based around a community clinic, was followed up from October, 1989, to September, 1992. 587 participants were HIV positive and 132 remained HIV negative. Set protocols were used to investigate common presentations. Cases were identified clinically and radiographically. Streptococcus pneumoniae and other pathogens were diagnosed by culture.

Findings Seventy-nine episodes of invasive pneumococcal disease were seen in the 587 HIV-positive women compared with one episode in the 132 seronegative women (relative risk $17.8,95 \% \mathrm{Cl} 2.5$ to 126.5 ). In seropositive women the incidence rate was 42.5 per 1000 person-years and the recurrence rate was 264 per 1000 person-years. By serotyping, most recurrent events were re-infection. A wide spectrum of HIV-related pneumococcal disease was seen: only $56 \%$ of cases were pneumonia; sinusitis was seen in $30 \%$ of cases, and occult bacteraemia, a novel adult presentation, in 11\%. Despite forty-two bacteraemic

Clinical Research Centre (C F Gilks MRCP, S A OjoO MRCP,

$J \mathrm{C}$ Ojoo $\mathrm{MBChB}$ ) and Centre for Microbiology Research (R J Brindle DM, J Paul MRCPath, B I F Batchelor FIBMS, J N Kimari, R Newnham flBMS), Kenya Medical Research Institute, Nairobi, Kenya; Department of Medical Microbiology, University of Nairobi (J Bwayo MB, F A Plummer MD); University of Winnipeg, Manitoba, Canada ( $F$ A Plummer); Centre for Tropical Medicine,

University of Oxford, Oxford, UK (C F Gilks, D A Warrell FRCP)

Correspondence to: $\mathrm{Dr}$ Charles Gilks, Liverpool School of Tropical Medicine, Liverpool L3 5QA, UK episodes, no deaths were attributable to Strep pneumoniae. At first presentation the mean CD4 cell count was 302/ $\mu \mathrm{L}$ (SD 191) and was $171 / \mu \mathrm{L}$ (105) for recurrent episodes. During acute Strep pneumoniae infection the CD4 cell count was reversibly suppressed (mean fall in sixteen episodes, $105 / \mu L$ [123]). The neutrophil response to acute infection was blunted and was correlated with CD4 count $(r=0.50,95 \% \mathrm{Cl} 0.29$ to 0.66$)$. Strep pneumoniae caused more disease, at an earlier stage of HIV immunosuppression, than Mycobacterium tuberculosis or non-typhi salmonellae.

Interpretation Our study highlights the importance of the pneumococcus as an early but readily treatable complication of HIV infection in sub-Saharan Africa.

Lancet 1996; 347: 718-23

\section{Introduction}

Sub-Saharan Africa currently bears the brunt of the HIV epidemic. ${ }^{`}$ Most attention clinically has been given to the interaction of HIV and Mycobacterium tuberculosis. Surprisingly little is known about the importance of other high-grade bacterial infections during HIV infection. ${ }^{2}$ In Africa, lobar (pneumococcal) pneumonia is a leading cause of hospital admission, particularly for young men. ${ }^{3}$ Although Streptococcus pneumoniae bacteraemia, ${ }^{4,5}$ pneumonia, ${ }^{6-9}$ and fatal meningitis ${ }^{10}$ are associated with HIV infection, the extent of interaction is unclear. We therefore studied the occurrence and clinical spectrum of bacterial and mycobacterial diseases during HIV infection in a cohort of female sex-workers in Nairobi. Here we present our data on invasive pneumococcal disease in particular.

\section{Cohort and methods}

\section{Cohort}

Between October, 1989, and September, 1992, we followed up an established cohort of female sex-workers in Nairobi. Recruitment to the cohort started in 1985 and contmues. Women who live and work by selling sex in Pumwani, a poor 